\title{
Influenza Vaccination Campaign in Military Hospitals: The Example of Najran Armed Forces Hospital: Attitudes and Uptake of Medical and Para Medical Staff
}

\author{
Imed Harrabi ${ }^{*}$, Saad Al Ghamdi² \\ ${ }^{1}$ Preventive Medicine Department, Najran University, Najran, KSA \\ ${ }^{2}$ Family and Community Medicine Center, Najran Armed Forces Hospital, Najran, KSA \\ Email:*imed_harrabi@yahoo.fr
}

How to cite this paper: Harrabi, I. and $\mathrm{Al}$ Ghamdi, S. (2019) Influenza Vaccination Campaign in Military Hospitals: The Example of Najran Armed Forces Hospital: Attitudes and Uptake of Medical and Para Medical Staff. Open Journal of Preventive Medicine, 9, 155-161.

https://doi.org/10.4236/ojpm.2019.912014

Received: December 10, 2019

Accepted: December 21, 2019

Published: December 24, 2019

Copyright $\odot 2019$ by author(s) and Scientific Research Publishing Inc. This work is licensed under the Creative Commons Attribution International License (CC BY 4.0).

http://creativecommons.org/licenses/by/4.0/

\begin{abstract}
Background: Because of their working environment, healthcare professionals (HCPs) are known to be at risk of contracting influenza virus from their patients and at the same time, act as a source of transmission to patients under their care. Successful Flu vaccination campaign among Health Care Workers can contribute to a large herd immunity in hospitals. Objective: This study was conducted to assess HCPs' attitudes towards influenza vaccination as well as the main predictors for not getting vaccinated. Methods: A cross-sectional study was carried out among HCPs practicing at Najran Armed Forces Hospital during flu vaccination campaign (2018-2019). The target population was composed of medical and para medical staff. Self administered pre-tested questionnaire was used to collect information about health workers' attitudes towards flu vaccine. Results: Our study showed that $74 \%$ of the studied population were vaccinated during the last flu vaccination campaign. The main motivation of the staff to get vaccinated was a personal conviction for $71.4 \%$, to avoid administrative sanctions for $7.1 \%$ and to have good relation with the administration for $5.1 \%$ of them. The probability of not getting vaccinated were significantly multiplied by 2.47 ; CI $95 \%=[1.15-5.32]$ among males compared to females and also it was significantly multiplied by 2.31 ; CI $95 \%=$ [1.07 - 4.9] among muslims compared to non muslims. Conclusion: The global flu vaccination rate in our study could be considered as acceptable to achieve herd immunity, more efforts needed in the future campaigns to convince especially male and muslim staff to take the flu vaccine.
\end{abstract}

\section{Keywords}

Flu Vaccine, Health Care Workers, Najran 


\section{Introduction}

The trend of high rates of morbidity and mortality related to influenza among high risk population could be considered as a public health problem [1]. Early prevention strategies such as an effective Flu vaccination are the best way to reduce health issues related to influenza [2]. It is considered as evidence that flu vaccine protect not only high risk population but also healthy people [3]. Medical and para medical staff could be considered as a high-risk category due to their proximity to patients. In fact, they can play the role of receivers or transmitters of flu disease. The flu epidemic risk is higher in medical institutions in case of absence of flu vaccination campaign including both staff and patients [4] [5]. Early detection and proper treatment of flu symptoms among health staff is an important action to reduce the risk of flu transmission to patients and their colleagues [5]. Sick leave due to influenza and per consequence a decrease of health staff productivity could be easily reduced by flu vaccine campaign among all healthcare workers in the same institution [6], it also contributes to a large herd immunity [7] [8] [9]. In recognition of this fact, in KSA the Ministry of Health and Ministry of defense recommended vaccinating all HCP against influenza on a routine annual basis. Rigorous annual flu vaccination campaigns have been started for many years in all military hospitals under the supervision and high coordination of MSD Center for Infection Prevention and Control.

At Najran Armed Forces Hospital, although the acceptable coverage flu vaccination rate (80\%) during the last campaign 2018-2019, there is no research evidence that specifically looks at HCPs' attitudes towards influenza vaccination. Therefore, this study was conducted to assess HCPs' attitudes towards influenza vaccination as well as the main predictors for not getting vaccinated.

\section{Methods}

A cross-sectional study was carried out among HCPs practicing at Najran Armed Forces Hospital during March to April 2019.

The target population was composed of medical and para medical staff. The sample size needed for the study was estimated to 200 based on confidence level of $95 \%$, margin of error $7 \%$ and expected prevalence of positive attitudes towards flu vaccine $50 \%$.

A convenience sampling method was adopted in medical and para medical departments for data collection. Participation in the study was voluntary. Verbal consent was obtained from all participants after the rationale of the study was explained.

Self administered pre-tested questionnaire was used to collect information about health workers attitudes towards flu vaccine. The questionnaire was developed using items derived from a previous review of health care workers' attitude to flu vaccine.

The questionnaires include items about beliefs and attitudes towards flu vaccination scored on a five-point likert scale. The questionnaire was presented to 
participants in a random order.

Data were coded and entered as nominal and ordinal variables using SPSS. 11.0.

T-test was used to compare means of attitudes scores between vaccinated and unvaccinated groups 5\% was fixed as level of statistical significance.

Logistic regression analysis was used to identify predictors of not getting vaccinated.

\section{Ethical Approval}

Ethical approval was obtained from the local research and ethics committee of Najran Armed Forces Hospital.

\section{Results}

Distributed questionnaire forms were collected with a $73 \%$ participation rate. A total of 146 Health Care Workers (HCW) with a mean age of $36.13 \pm 8.11$ years (range 25 to 59 years) participated in the survey, of whom 93 (63.7\%) were women. The study included 35 (24\%) physicians, 77 (52.7\%) nurses, 22 (15.1\%) technicians and $12(8.2 \%)$ other categories including medical secretaries (Table 1). Among the study participants, 108 (74\%) were vaccinated during the last campaign 2018/2019.

The main motivation of the staff to get vaccinated was a personal conviction for $71.4 \%$, to avoid administrative sanctions for $7.1 \%$ and to have good relation with the administration for $5.1 \%$ of them (Table 2 ).

Table 1. General characteristics of the studied population.

\begin{tabular}{|c|c|c|}
\hline Demographic Variables & Number & Percentage \\
\hline \multicolumn{3}{|l|}{ Gender $(n=144)$} \\
\hline Male & 51 & 35.4 \\
\hline Female & 93 & 64.6 \\
\hline \multicolumn{3}{|l|}{ Marital Status $(n=145)$} \\
\hline Single & 49 & 33.8 \\
\hline Married & 96 & 66.2 \\
\hline \multicolumn{3}{|l|}{ Age (Years) $(n=132)$} \\
\hline$<35$ & 74 & 56.1 \\
\hline$\geq 35$ & 58 & 43.9 \\
\hline \multicolumn{3}{|l|}{ Years in Najran $(n=144)$} \\
\hline$<1$ year & 32 & 22.2 \\
\hline $1-5$ years & 67 & 46.5 \\
\hline$>5 \mathrm{Yrs}$ & 45 & 31.3 \\
\hline \multicolumn{3}{|l|}{ Religion $(n=142)$} \\
\hline Muslim & 61 & 43.0 \\
\hline Non-muslim & 81 & 57.0 \\
\hline
\end{tabular}


Vaccinated staff were significantly more likely to agree that having Flu Vaccine sets a good example to patients $\mathrm{p}=0.01$. They felt more confident in advising patients about being vaccinated $p=0.02$ and they felt that it was more easy to get the Flu Vaccine where they work $p=0.01$. Staff who had not had the Flu Vaccine were more likely to think that that the Flu Vaccine would make them feel unwell $p=0.03$ (Table 3).

In the univariate logistic regression models, gender and religion were significant predictors of not getting vaccinated among the studied population. The probability of not getting vaccinated was significantly multiplied by 2.47 ; CI $95 \%=[1.15-5.32]$ among males compared to females and also it was significantly multiplied by 2.31 ; CI $95 \%=[1.07-4.9]$ among muslims compared to non muslims (Table 4).

Marital status and age were associated with a high probability of not getting vaccinated without statistical significance. In fact, married and young staffs (less than 35 years) had respectively probability of 1.60 ; CI $95 \%=[0.7-3.65]$ and 1.62 ; CI $95 \%=[0.72-3.62]$.

\section{Discussion}

Influenza vaccination among HCPs needs to be regularly monitored. An incentive for vaccination and an intensified advertising campaign have been shown to improve vaccination rates in the workplace [10] [11]. A mandatory influenza vaccination policy, exempting only those HCPs with a medical contraindication,

Table 2. The main motivation of the staff to get vaccinated.

\begin{tabular}{ccc}
\hline Items & N & $\%$ \\
\hline Personal conviction & 70 & 71.4 \\
To avoid administrative sanction & 07 & 7.1 \\
To have good relation with administration & 05 & 05.1 \\
Others & 16 & 16.3 \\
\hline
\end{tabular}

Table 3. Comparison of mean attitudes towards Flu Vaccine between vaccinated and unvaccinated groups.

\begin{tabular}{lccc}
\hline & $\begin{array}{c}\text { Vaccinated } \\
\text { Mean Score } \\
\text { (SD) }\end{array}$ & $\begin{array}{c}\text { Mean Score } \\
\text { (SD) }\end{array}$ & $\begin{array}{c}\text { p: Degree of } \\
\text { Significance }\end{array}$ \\
\hline $\begin{array}{l}\text { 1. It was easy for me to get the flu vaccine where I work } \\
\text { 2. Flu Vaccine for staff is seen as important where I work }\end{array}$ & $\begin{array}{l}4.12(0.17) \\
\text { 3. The flu vaccine will protect me getting flu }\end{array}$ & $3.76(1.01)$ & 0.01 \\
4. I am confident advising patients about the flu vaccine & $2.25(0.94)$ & $3.70(1.22)$ & 0.03 \\
5. Having flu vaccine sets a good example to patients & $4.15(0.75)$ & $3.73(1.28)$ & 0.01 \\
6. The flu vaccine will make me unwell & $3.83(0.93)$ & $3.41(1.27)$ & 0.03 \\
7. I am likely to come to work even if I am unwell & $3.31(1.11)$ & $3.74(0.91)$ & 0.03 \\
\hline
\end{tabular}


Table 4. Socio-demographic predictors of not getting vaccinated among the studied population.

\begin{tabular}{ccc}
\hline & OR & $\mathrm{CI}_{95 \%}$ \\
Gender & 1 & - \\
Female & 2.47 & $(1.15-5.32)$ \\
Male & & \\
Religion & 1 & $(1.07-4.9)$ \\
Non muslim & 2.31 & \\
Muslim & & - \\
Marital Status & 1 & $(0.70-3.65)$ \\
Single & 1.6 & \\
Married & & $(0.72-3.63)$ \\
Age (Years) & 1 & \\
$\geq 35$ & 1.62 & \\
$<35$ & & \\
\hline
\end{tabular}

has been demonstrated to be highly effective in achieving high vaccine coverage [12] [13]. It was reported that the use of a mask as a mandatory for staff refusing to take the flu vaccine is an alternative preventive strategy [12].

Our study showed that $74 \%$ of the studied population were vaccinated during the last flu vaccination campaign 2018-2019. This rate could be considered as acceptable to achieve herd immunity within our hospital. In fact, it has been previously recommended that $80 \%$ of the HCPs must be vaccinated to achieve herd immunity within the healthcare facilities [14].

Findings from the current study suggest that the main motivation of HCPs to get vaccinated was a personal conviction. This result is in consistence with other studies that identified the main reason for taking the flu vaccine by HCPs to be for self protection [15]. However, a study conducted in Australia revealed that the most important reason for vaccine uptake was to protect their patients against transmission of the disease, where almost three quarters of the participants identified patient protection to be the main reason for taking up the flu vaccine [16].

The probability of not getting vaccinated was significantly multiplied by 2.31 ; CI 95\% = [1.07 - 4.9] among muslims compared to non muslims. This may be in relation to the components of the flu vaccines.

In KSA, the Saudi Food and Drug Authority had no objection to the general use of Flu vaccines. Future researches are needed to investigate in depth the main factors that could explain this phenomenon [17].

The current study could be considered as a pilot study due to the limited number of medical and para medical staff that have accepted to share their attitudes regarding flu vaccine. Multicentric study will be conducted in the future with more involvement of other military hospitals in the Kingdom. 


\section{Conflicts of Interest}

The authors declare no conflicts of interest regarding the publication of this paper.

\section{References}

[1] Bailey, E.S., Choi, J.Y., Fieldhouse, J.K., Borkenhagen, L.K., Zemke, J., Zhang, D. and Gray, G.C. (2018) The Continual Threat of Influenza Virus Infections at the Human-Animal Interface: What Is New from a One Health Perspective? Evolution, Medicine, and Public Health, 2018, 192-198. https://doi.org/10.1093/emph/eoy013

[2] Grohskopf, L.A., Sokolow, L.Z., Broder, K.R., Walter, E.B., Fry, A.M. and Jernigan, D.B. (2018) Prevention and Control of Seasonal Influenza with Vaccines: Recommendations of the Advisory Committee on Immunization Practices-United States, 2018-19 Influenza Season. Morbidity and Mortality Weekly Recommendations and Report, 67, 1-20. https://doi.org/10.15585/mmwr.rr6703a1

[3] Osterholm, M.T., Kelley, N.S., Sommer, A. and Belongia, E.A. (2012) Efficacy and Effectiveness of Influenza Vaccines: A Systematic Review and Meta-Analysis. The Lancet Infectious Diseases, 12, 36-44. https://doi.org/10.1016/S1473-3099(11)70295-X

[4] Mendoza-García, J.L., Quirós-González, V., Jiménez-Rodríguez, M., Haro-Pérez, A., Gutiérrez Zufiaurre, M.N. and Rodríguez-Pérez, P. (2018) Impact of Nosocomial Transmission of Influenza Virus in an Acute Hospital. Revista Española de Salud Pública, 10, 92.

[5] Huzly, D., Kurz, S., Ebner, W., Dettenkofer, M. and Panning, M. (2015) Characterization of Nosocomial and Community-Acquired Influenza in a Large University Hospital during Two Consecutive Influenza Seasons. Journal of Clinical Virology, 73, 47-51. https://doi.org/10.1016/j.jcv.2015.10.016

[6] Van Buynder, P.G., Konrad, S., Kersteins, F., Preston, E., Brown, P.D., Keen, D. and Murray, N.J. (2015) Healthcare Worker Influenza Immunization Vaccinate or Mask Policy: Strategies for Cost Effective Implementation and Subsequent Reductions in Staff Absenteeism Due to Illness. Vaccine, 33, 1625-1628.

https://doi.org/10.1016/j.vaccine.2015.01.048

[7] Amodio, E., Restivo, V., Firenze, A., Mammina, C., Tramuto, F. and Vitale, F. (2014) Can Influenza Vaccination Coverage among Healthcare Workers Influence the Risk of Nosocomial Influenza-Like Illness in Hospitalized Patients? Journal of Hospital Infection, 86, 182-187. https://doi.org/10.1016/j.jhin.2014.01.005

[8] Ahmed, F., Lindley, M.C., Allred, N., Weinbaum, C.M. and Grohskopf, L. (2014) Effect of Influenza Vaccination of Healthcare Personnel on Morbidity and Mortality among Patients: Systematic Review and Grading of Evidence. Clinical Infectious Diseases, 58, 50-57. https://doi.org/10.1093/cid/cit580

[9] De Serres, G., Skowronski, D.M., Ward, B.J., Gardam, M., Lemieux, C., Yassi, A., Patrick, D.M., Krajden, M., Loeb, M., Collignon, P. and Carrat, F. (2017) Influenza Vaccination of Healthcare Workers: Critical Analysis of the Evidence for Patient Benefit Underpinning Policies of Enforcement. PLoS ONE, 12, e0163586. https://doi.org/10.1371/journal.pone.0163586

[10] Baskin, E. (2018) Increasing Influenza Vaccination Rates via Low Cost Messaging Interventions. PLOS ONE, 13, e0192594. https://doi.org/10.1371/journal.pone.0192594

[11] Graves, M.A., Harris, J.R., Hannon, P.A., Hammerback, K., Ahmed, F. and Zhou, C. 
(2014) Workplace-Based Influenza Vaccination Promotion Practices among Large Employers in the United States. Journal of Occupational and Environmental Medicine, 56, 397-402. https://doi.org/10.1097/JOM.0000000000000115

[12] Babcock, H.M., Gemeinhart, N., Jones, M., Dunagan, W.C. and Woeltje, K.F. (2010) Mandatory Influenza Vaccination of Health Care Workers: Translating Policy to Practice. Clinical Infectious Diseases, 50, 459-464. https://doi.org/10.1086/650752

[13] Pavia, A.T. (2010) Mandate to Protect Patients from Health Care-Associated Influenza. Clinical Infectious Diseases, 50, 465-467. https://doi.org/10.1086/650753

[14] Plans-Rubió, P. (2012) The Vaccination Coverage Required to Establish Herd Immunity against Influenza Viruses. Preventive Medicine, 55, 72-77. https://doi.org/10.1016/j.ypmed.2012.02.015

[15] Durando, P., Alicino, C., Dini, G., et al. (2016) Determinants of Adherence to Seasonal Influenza Vaccination among Healthcare Workers from an Italian Region: Results from a Cross-Sectional Study. BMJ Open, 6, e010779. https://doi.org/10.1136/bmjopen-2015-010779

[16] Seale, H., Leask, J. and MacIntyre, C.R. (2010) Attitudes amongst Australian Hospital Healthcare Workers towards Seasonal Influenza and Vaccination. Influenza and Other Respiratory Viruses, 4, 41-46. https://doi.org/10.1111/j.1750-2659.2009.00112.x

[17] Kocourkova, A., Honegr, J., Kuca, K. and Danova, J. (2017) Vaccine Ingredients: Components that Influence Vaccine Efficacy. Mini-Reviews in Medicinal Chemistry, 17, 451-466. https://doi.org/10.2174/1389557516666160801103303 